\section{Effects of a conditioned taste aversion on schedule-induced polydipsia'}

DAVID ROLL, ROBERTW. SCHAEFFER, and JAMES C. SMITH, Florida State University, Tallahassee, Fla. 32306

Rats that became polydipsic on water under a FFI-60 food schedule were switched to a saccharin solution. After drinking saccharin, the Ss were exposed to ionizing radiation. Although this procedure produces a marked aversion to saccharin in thirst motivated rats following a single exposure, repeated pairings of the saccharin solution and ionizing radiation were needed to reduce the high drinking levels generated by the intermittent food schedule. These findings suggest that schedule-induced polydipsia is a strong motivational state.

The motivational properties of scheduleinduced polydipsia have been demonstrated by Falk (1966). He trained rats to press a bar for food pellets on a VI 1-min schedule of reinforcement. Water was freely available to Ss in the home cages, but in the experimental chambers the delivery of $0.1 \mathrm{ml}$ of water was made contingent upon bar pressing. In this situation, Ss maintained a polydipsic level of drinking even though water was contingent on reinforcement schedules that varied from FR 1 to FR 50. Since the Ss were not water-deprived in the home cages, the high rate of bar pressing for water that was maintained in the experimental chambers clearly demonstrated that the intermittent food schedule produced a strong motivation to drink.

An alternate method of demonstrating the strength of schedule-induced polydipsia would be to produce a competing motivational state in Ss, once they are polydipsic, to not drink the solution. Although quinine solutions are normally avoided, adulterating the drinking fluid with quinine fails to abolish schedule-induced polydipsia (Segal \& Deadwyler, 1965). Classically conditioned aversions to distinctively flavored fluids, with ionizing radiation as the aversive motivating stimulus, can also be employed to induce aversions to normally preferred solutions. Exposing rats to X-rays or $\mathrm{Co}^{60}$ gamma rays, shortly before or after they have consumed small amounts of a $0.1 \%$ saccharin solution, reverses the normal preference of saccharin over water and dramatically reduces the amount of saccharin consumed when that is the only solution available (see Kimeldorf \& Hunt, 1961). When tested $48 \mathrm{~h}$ after a pairing of experimental conditions. procedure normally decreases the probability of drinking a particular fluid, superimposing the latter procedure on the former procedure should reveal the relative strengths of the two motivational operations.

\section{SUBJECTS}

Four female SDD/DR albino rats from saccharin consumption with $54 \mathrm{R} \mathrm{Co}^{60}$, irradiated rats drank less than $1 \mathrm{~g}$ of saccharin solution, while sham irradiated controls drank an average of $26 \mathrm{~g}$ during the same test period (Garcia \& Kimeldorf, 1960).

The purpose of the present experiment was to test the effects of the conditioned saccharin aversion procedure upon scheduleinduced polydipsia, when the only drinking solution available in the test chamber was saccharin. Since intermittent schedules of food delivery increase the probability of drinking, and the conditioned taste aversion the Dublin breeding laboratories were used. They were maintained at $80 \%$ of their free feeding body weight by food deprivation. Although most of the daily food ration was obtained in the experimental session, it was necessary to add about $5 \mathrm{~g}$ of lab chow per day in the home cages to maintain the proper body weight.

\section{APPARATUS}

The Ss were placed in standard LVE Model 1548 test chambers at the same time each day. Standard 45.mg Noyes food pellets were used as reinforcers. A water bottle was attached to the test chamber, and
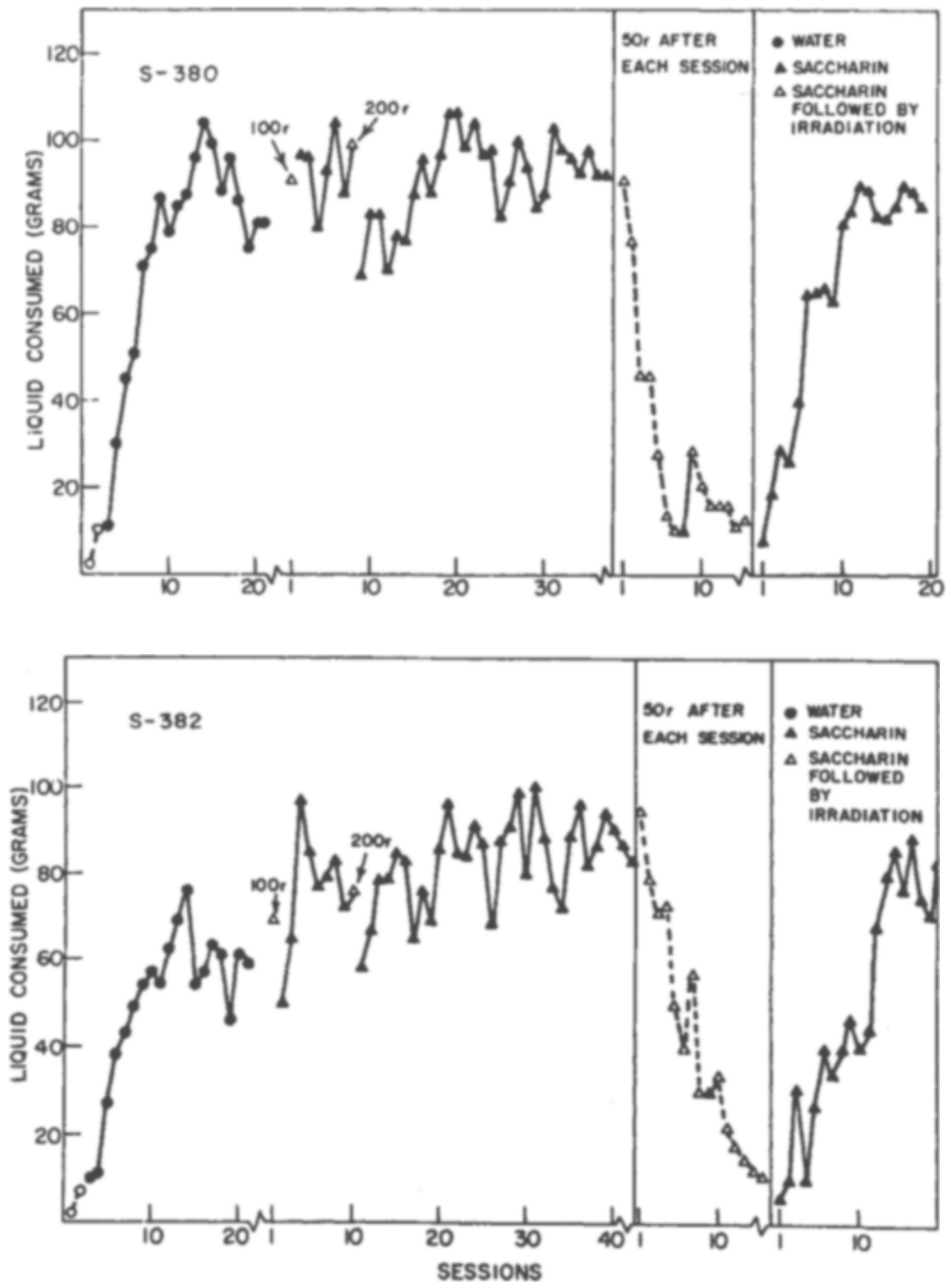

Fig. 1. Total liquid consumption for each session by experimental Ss under all 
the drinking tube was accessible through a $1 / 2$-in. diam hole placed 3 in. to the right of the food cup. White noise was continuously present to mask ex traneous noises.

During irradiation or sham trials the Ss were placed in individual compartments of a wooden box with a fine copper screen between the source and the animal. Gamma radiation was produced by $\mathrm{Co}^{60}$ from a Model $150 \mathrm{C}$ Gammabeam Irradiator (Atomic Energy of Canada). A target-to-S distance of $27 \mathrm{in}$. was used for all exposures, resulting in a dose rate of $2.1 \mathrm{R} / \mathrm{sec}$.

PROCEDURE AND RESULTS

The first two sessions served to adapt $S$ s to the apparatus and food pellets. The Ss were placed in the test chamber for $21 / 2 \mathrm{~h}$ with 150 pellets in the food cup at the beginning of the sessions. Water intake values were observed by weighing the bottles before and after each session. Licks on the water tube were monitored by standard drinkometer circuits, and recorded on counters and cumulative recorders.

On Day 3 , intermittent food delivery was
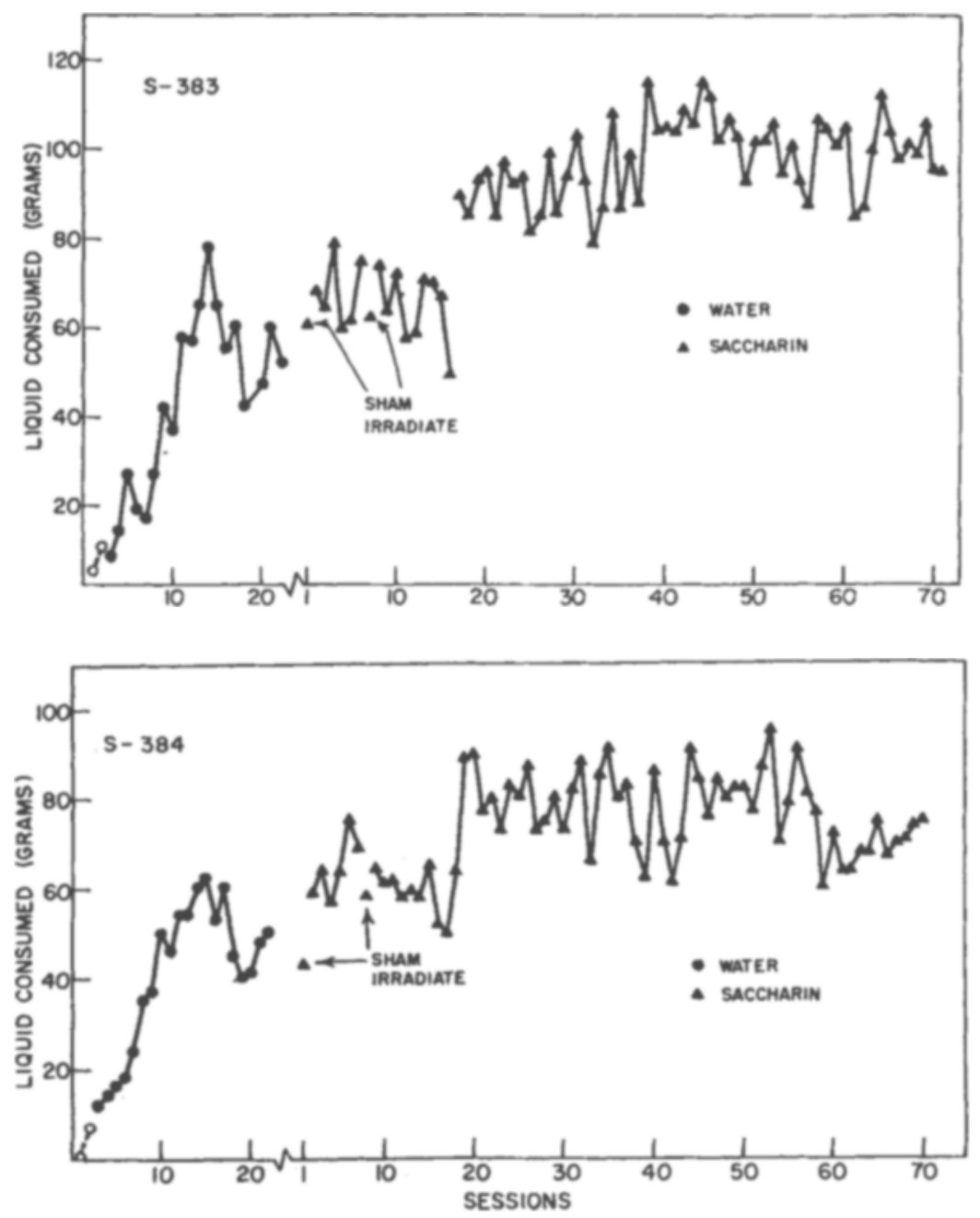

Fig. 2. Total liquid consumption for each session by control Ss under all experimental conditions. \& Bedarf, 1967).

Polydipsia emerged rapidly for all Ss. Cumulative records showed the typical immediate post-pellet water drinking, followed by a pause before delivery of the next pellet. When water drinking stabilized, the drinking fluid was changed from water to a $0.1 \%$ sodium saccharin solution for the remainder of the experiment. Immediately after the first saccharin session, Ss 380 and 382 were exposed to $100 \mathrm{R} \mathrm{Co}^{60}$. Ss 383 and 384 were then placed in front of the irradiator, but were not exposed to gamma rays. Figure 1 shows that the saccharinradiation pairing produced only a slight decrease in the amount of saccharin consumed by S 382 in later sessions, and begun. One pellet was delivered each minute independently of Ss' behavior (FFI 1). Each session ended when 150 pellets had been delivered. Water rather than saccharin was available to the Ss for the initial development of polydipsic behavior, because novelty of the taste substance is critical for reliable conditioned taste aversion (Revusky the experiment, with no significant shifts following sham exposures. The broken line preceding Session 17 for $S 383$ indicates the repair of the reinforcement mechanism which previously did not deliver all programmed reinforcements.

\section{DISCUSSION}

The present data support Falk's (1966) contention that schedule-induced polydipsia has strong motivational properties. Rats deprived of all liquid for $48 \mathrm{~h}$ after a saccharin-radiation pairing $\left(54 \mathrm{R} \mathrm{Co}^{60}\right)$ consume almost no saccharin in a 6 -h test period (Garcia \& Kimeldorf, 1960), and rats will show a strong preference for water over saccharin in a two-bottle preference test for as long as $\mathbf{3 0}$ days following a single pairing of saccharin consumption with $57 \mathrm{R} \mathrm{Co}^{68}$ (Garcia, Kimeldorf, \& Koelling, 1955). By contrast, polydipsic rats in the present experiment showed no decrement of saccharin consumption in the sessions following their initial exposure to $100 \mathrm{R}$. It may be argued that the resistance to changes in drinking level was a result of making saccharin the only solution available in the test chamber. However, testing occurred for only $2.5 \mathrm{~h}$ each day while water was available in the home cage for $21.5 \mathrm{~h}$ daily, and the Ss could easily have obtained their total water requirements in the home cages.

The decrement of drinking with repeated saccharin-radiation pairings shows that the conditioned taste aversion is a viable procedure for reducing drinking levels. The fact that the conditioning procedure rather than some other factor accounted for diminished drinking was demonstrated by recovery of the experimental Ss with cessation of radiation exposures, and by the 
stability of the control Ss throughout the experiment. Radiation sickness cannot explain the decrement since both $\mathrm{Ss}$ ate all food pellets delivered in each session.

Since $S$ s that are fluid deprived avoid fluids that have been previously paired on a single occasion with ionizing radiation, even when that fluid is the only solution available, it is apparent that radiationinduced aversion produces a motivational

\section{REFERENCES}

FALK, J. The motivational properties of schedule-induced polydipsia. Journal of the Experimental Analysis of Behavior, 1966, 9, 19-25.

GARCIA, J., KIMELDORF, D., \& KOELLING, R. Conditioned aversion to saccharin resulting from exposure to gamma radiation. Science, $1955,122,157-158$.

GARCIA, J., \& KIMELDORF, D. Some factors which influence radiation-conditioned behavior in rats. Radiation Research, 1960, 12,719-722.

GARCIA, J., KIMELDORF, D., \& HUNT, E. The use of ionizing radiation as a motivating state that overrides the thirst motivation produced by $48 \mathrm{~h}$ water deprivation. The fact that this same conditioned aversion procedure does not produce a decrement in the high fluid intake levels induced by intermittent food schedules, and that repeated conditioning was required to reduce drinking, clearly attests to the strength of the motivational state induced by intermittent scheduling of food.

stimulus. Psychological Review, 1961, 68, 383-395.

REVUSKY, S., \& BEDARF, E. W. Association of an illness with the prior ingestion of novel foods. Science, 1967, 155, 219-220.

SEGAL, E. F., \& DEADWYLER, S. Determinants of polydipsia. VI. Taste of drinking solution on DRL. Psychonomic Science, 1965, 3, 101-102. NOTE

1. Supported by Public Health Service Research Grant MH-08775 from the National Institute of Mental Health and by Contracts AT- $(40-1)-2903$ and AT-(40-1)-02690 with the Division of Biology and Medicine, U.S. Atomic Energy Commission. opposed to the reinforced trials. Such results would appear analogous to the FE obtained in double runway studies and could be viewed as representing a form of residual frustration, since the energizing effect on behavior in both situations follows nonreward and is independent of cues associated with primary frustration.

Since a number of FE studies (e.g., McCain \& McVean, 1967; Wagner, 1959) have found faster partially reinforced running speeds in the second alley following the reinforced as well as the nonreinforced trials, as compared to continuous reinforcement, it would seem reasonable to ask whether activity might be greater in partially rewarded Ss following the reinforced trials.

\section{SUBJECTS}

The Ss were 20 experimentally naive male hooded rats from the inbred colony maintained at Washington State University. Animals were housed in two cages of $7 \mathrm{Ss}$ each and one of 6 , and were approximately 180 days old at the beginning of the experiment.

\section{APPARATUS}

The apparatus consisted of two flat black 55-in. parallel plywood straight alleys which were 4 in. high, with 9-in. start boxes and 10-in. goal boxes which were equipment with standard guillotine doors. Physically separate from the alleys was a white $22 \times 22$ in. open-field maze constructed of fiberboard. The maze was $12 \frac{1}{2}$ in. deep, with the top $43 / 4$ in. consisting of a brown paper barrier. The floor of the maze was divided into 25 squares by thin black lines. Electric counters were used to record activity, and a stopwatch was used to measure trial durations in the open field.

\section{PROCEDURE}

Prior to the experiment, all Ss were $23 \mathrm{~h}$ food-deprived for 14 days, and were handled individually for 2-3 min over the last 8 days. Ss were also given about $30 \mathrm{~min}$ exploration time in their individual waiting cages on each of the last 8 days, and were prefed with 97-mg Noyes reward pellets over the last 7 days. Water was continuously available in the home cages at all times.

Training and testing were carried out over 19 consecutive days. On Day 1 of training each $S$ was given $10 \mathrm{~min}$ of free exploration in one of the straight alleys, and the deprivation schedule was shifted to and maintained at $22 \frac{1}{2} \mathrm{~h}$. During training, Ss were run in either straight alley for four 97-mg Noyes pellets on each of 23 trials. Three trials were run on Day 2 and four trials per day were given on Days 3 through 7 with an intertrial interval of approximately $15 \mathrm{~min}$

Following training the Ss were randomly divided into two groups. The partial reinforcement (PR) group received food on
Interpreting the effects of partial reinforcement in terms of a motivational state physically separate open-field maze following each trial, significantly more activity was observed following the nonreinforced as 